\title{
Heat Rejection Systems Utilizing Composites and Heat Pipes: Design and Performance Testing
}

\author{
Donald A. Jaworske ${ }^{1}$ and Duane E. Beach ${ }^{2}$ \\ NASA Glenn Research Center, Cleveland, Ohio, 44135 \\ and \\ James L. Sanzi ${ }^{3}$ \\ Sest Inc., Middleburgh Heights, Ohio, 44130
}

\begin{abstract}
Polymer matrix composites offer the promise of reducing the mass and increasing the performance of future heat rejection systems. With lifetimes for heat rejection systems reaching a decade or more in a micrometeoroid environment, use of multiple heat pipes for fault tolerant design is compelling. The combination of polymer matrix composites and heat pipes is of particular interest for heat rejection systems operating on the lunar surface. A technology development effort is under way to study the performance of two radiator demonstration units manufactured with different polymer matrix composite face sheet resin and bonding adhesives, along with different titanium-water heat pipe designs. Common to the two radiator demonstration units is the use of high thermal conductivity fibers in the face sheets and high thermal conductivity graphite saddles within a light weight aluminum honeycomb core. Testing of the radiator demonstration units included thermal vacuum exposure and thermal vacuum exposure with a simulated heat pipe failure. Steady state performance data were obtained at different operating temperatures to identify heat transfer and thermal resistance characteristics. Heat pipe failure was simulated by removing the input power from an individual heat pipe in order to identify the diminished performance characteristics of the entire panel after a micrometeoroid strike. Freeze-thaw performance was also of interest. This paper presents a summary of the two radiator demonstration units manufactured to support this technology development effort along with the thermal performance characteristics obtained to date. Future work will also be discussed.
\end{abstract}

\section{Nomenclature}

$\begin{array}{ll}m m & =\text { millimeter } \\ m & =\text { meter } \\ T & =\text { temperature, } \mathrm{K} \\ W & =\text { watts }\end{array}$

\section{Introduction}

$\mathrm{H}$ eat rejection systems designed for long term use need to be durable to the space environment. One threat to such systems is the threat of micrometeoroid impact on tubing with subsequent loss of coolant. To accommodate the inevitability of micrometeoroid impacts, system design is driven toward the use of individual heat pipes, whereby a micrometeoroid impact on a given heat pipe removes only a small portion of the total cooling capability. ${ }^{1-2}$ With this design philosophy in mind, development of heat rejection systems utilizing heat pipes is of ongoing interest.

\footnotetext{
${ }^{1}$ Physicist, Space Environmental Durability Branch, 21000 Brookpark Rd., Cleveland, Ohio, AIAA Member.

${ }^{2}$ Thermal Engineer, Thermal Energy Conversion Branch, 21000 Brookpark Rd., Non-Member.

${ }^{3}$ Heat Transfer Engineer, Thermal Energy Conversion Branch, 21000 Brookpark Rd., AIAA Member.
} 
Heat rejection systems for power conversion systems utilizing a fission heat source need to reject heat at high temperatures, perhaps as high as $500 \mathrm{~K}$. One heat pipe system under consideration for such temperature conditions is the titanium-water heat pipe system. High temperature titanium-water heat pipes show great promise..$^{3-5}$ Titanium offers excellent strength and is easily machined into needed heat pipe cross sectional geometry. To minimize mass, and to provide sufficient support for deployment, panels composed of aluminum honeycomb sandwiched between two composite face sheets are currently of interest. Composite face sheets composed of high thermal conductivity fibers offer improved fin efficiency. ${ }^{6-7}$

A technology development effort was initiated under NASA's Prometheus Program to develop several technologies, including heat rejection systems utilizing titanium-water heat pipes. A part of the technology development effort was to design, fabricate, and test Radiator Demonstration Units (RDUs). RDU technology development remains important to NASA's Fission Surface Power goals and is ongoing. A test plan was developed to evaluate the RDUs. Thermal performance was evaluated in a liquid nitrogen cooled thermal vacuum chamber. Thermal performance was also compared to analytical predictions based on a thermal model utilizing the physical properties of the RDU constituent parts. This paper summarizes the results of the thermal performance evaluation to date, and identifies opportunities for improvement in future systems.

\section{Materials and Methods}

Glenn Research Center procured three RDU panels of similar construction, utilizing slightly different materials and heat pipe wick configurations. All panels utilized a honeycomb sandwich construction with three titaniumwater heat pipes embedded at an interval of $160 \mathrm{~mm}$. All panels were flat, rigid, and approximately $25.4 \mathrm{~mm}$ thick by $0.5 \mathrm{~m}$ wide and $1 \mathrm{~m}$ long. High thermal conductivity graphite fiber - polymer matrix composite face sheets, each 6 plies thick, were adhesively bonded to an aluminum honeycomb core utilizing an adhesive layer. The graphite fiber selected for construction was K13D2U from Mitsubishi. Although the graphite fiber was common to all three panels, different materials were used for the polymer matrix and adhesive, including, NASA-developed 6Fpolyimides with a phenylethynyl endcap (HFPE), Cytec 5250-4 bismaleimide (BMI), and Bryte EX 1551 cyanate ester, as summarized in Table $1 .^{8}$

Table 1. RDU Panel Materials.

\begin{tabular}{|l|c|c|}
\hline Panel & Resin Matrix & Adhesive \\
\hline A & HFPE & 5250-4 BMI \\
\hline B & 5250-4 BMI & 5250-4 BMI \\
\hline C & EX-1551 Cyanate Ester & EX-1551 Cyanate Ester \\
\hline
\end{tabular}

The thickness of the adhesive layer between heat pipe and foam, and between foam and face sheet, was estimated to be $0.1 \mathrm{~mm}$. Optical microscopy of sectioned samples provided guidance on the percent of surface area bonded in each case. The bond between polymer matrix composite and foam was found to be approximately $72 \%$ along the length of one cross section while the bond between foam and titanium was found to be approximately $40 \%$ along the length of the cross section. Given that the bond is really an area rather than a line, the areal fraction of bond contact is $(0.72)^{2}$ and $(0.40)^{2}$, respectively. Hence, the areal bond contact was estimated at 0.52 and 0.16 , respectively.

Thermal conductivity measurements were made at multiple temperatures on witness coupons of all three polymer matrix composites. The estimated thermal conductivities of the composite face sheets at $500 \mathrm{~K}$ are summarized in Table $2{ }^{8}$ For these measurements, $\mathrm{X}$ is perpendicular to the axis of the heat pipe, $\mathrm{Y}$ is parallel to the axis of the heat pipe, and $\mathrm{Z}$ is through the thickness of the face sheet material.

Table 2. Estimated Laminate Thermal Conductivity at $500 \mathrm{~K}$.

\begin{tabular}{|l|c|c|c|}
\hline Matrix & $\begin{array}{c}\text { A, HFPE } \\
\text { W/m K }\end{array}$ & $\begin{array}{c}\text { B, 5250-4 BMI } \\
\text { W/m K }\end{array}$ & $\begin{array}{c}\text { C, Cyanate Ester } \\
\text { W/m K K }\end{array}$ \\
\hline X (in plane) Long & 251 & 226 & 255 \\
\hline Y (in plane) Trans. & 63 & 57 & 65 \\
\hline Z (through plane) & 0.96 & 0.72 & 1.22 \\
\hline
\end{tabular}

In the following discussion, POCO is an acronym for Pure Oil Company. Within the honeycomb core, the $19 \mathrm{~mm}$ diameter commercially pure titanium heat pipes having a wall thickness of $1.25 \mathrm{~mm}$ were adhesively bonded to 
POCO graphite foam saddles which in turn were bonded to the polymer matrix composite face sheets. POCO graphite has a nominal thermal conductivity of $135 \mathrm{~W} / \mathrm{mK}$ out-of-plane, and $45 \mathrm{~W} / \mathrm{mK}$ in-plane, decreasing with increasing temperature. The saddles were constructed such that the high thermal conductivity orientation was placed from heat pipe to face sheet. The diagram in Figure 1 shows an exploded view of the salient features of the panel construction. A completed panel is shown in Figure 2, with evaporators to the far right.

\section{The High Thermal Conductivity Poco Foam Orientation is Toward the Skins / Through the Panel Thickness}

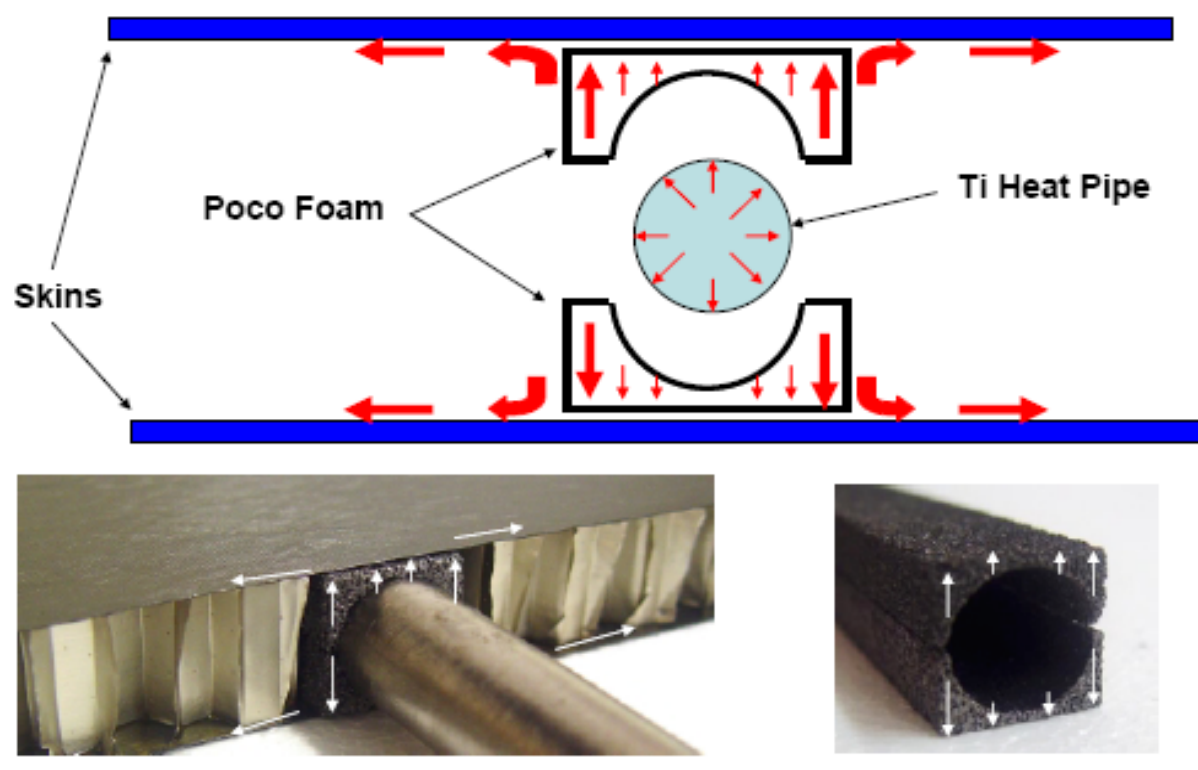

Figure 1. Construction details of the RDU panels.

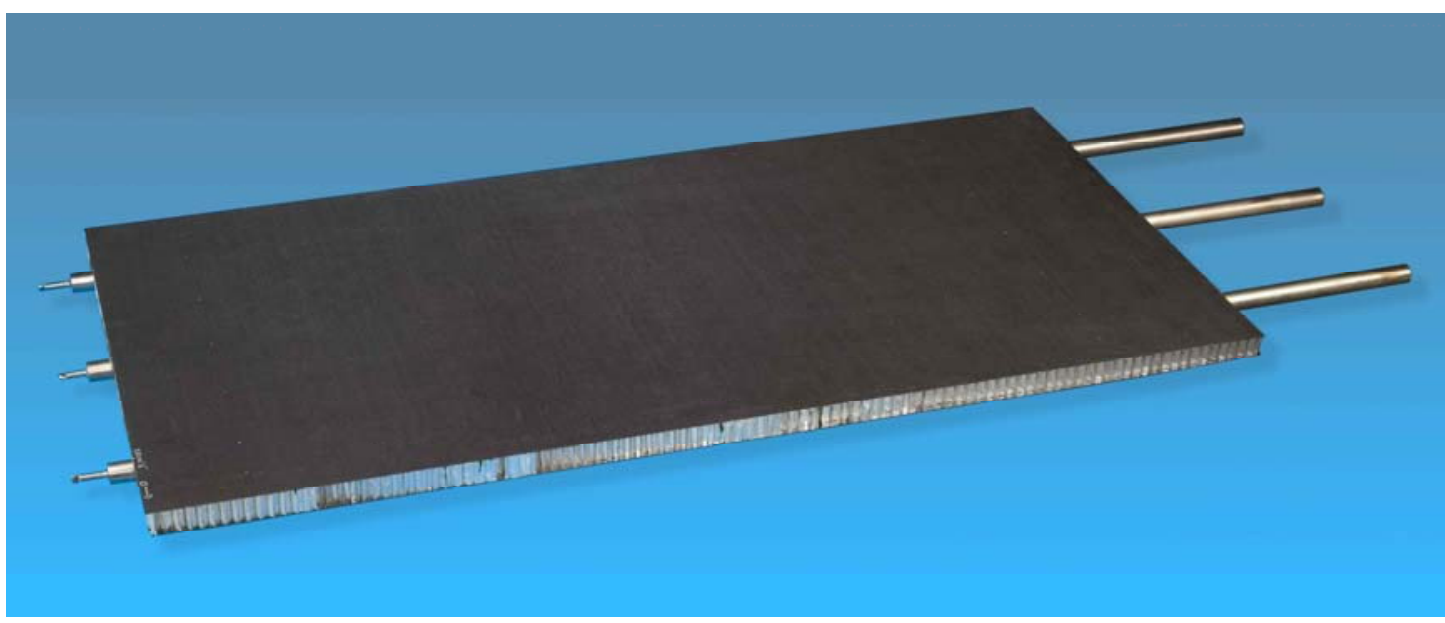

Figure 2. Overall view of one of the three RDU panels.

Also common to all three RDU panels was power and thermocouple instrumentation. The RDU panels were powered by mineral-insulated band heaters, four per evaporator, each $25 \mathrm{~mm}$ in length clamped to the evaporator 15 $\mathrm{mm}$ apart and capable of supplying 150 watts of power. Care was taken to wrap the band heaters in Kaowool ${ }^{\mathrm{TM}}$ and multilayer insulation to minimize heat loss. Sixty nine type $\mathrm{T}$ thermocouples were placed at strategic locations across the face of the panel, on the titanium heat pipes at either end of the condenser section, and on the evaporators 
near the heaters. All power and thermocouple instrumentation was monitored by a programmable logic controller, with data output sent to an Excel spreadsheet.

Unique to each panel were the heat pipe wick configurations. The heat pipes were manufactured by Advanced Cooling Technologies, Lancaster, PA. Solid axial groove heat pipe wick configurations were utilized in panels A and B, while a sintered powder metal axial groove heat pipe wick configuration was utilized in panel C. Heat pipes were fully tested prior to integration into panels, including thermal performance testing and hydrostatic pressure testing. Sufficient margin was provided in the heat pipe to withstand the vapor pressure of the working fluid at the maximum expected operating temperature of $530 \mathrm{~K}$. At this temperature, internal vapor pressure is $4.6 \times 10^{5} \mathrm{~Pa}$. Assembly of the panel constituents was accomplished utilizing a vacuum bagging process at ATK Space Systems, San Diego, CA.

Thermal vacuum testing was carried out in a vacuum facility equipped with a roughing pump, turbo pump, and cryopump working in concert to provide a pumping capacity on the order of 2000 liters/sec. The facility was also equipped with a liquid nitrogen cold wall, fully flooded with liquid nitrogen and operating at approximately $80 \mathrm{~K}$ when in use. Each instrumented panel was mounted in the vacuum chamber and held nominally horizontal in the plane of the face sheet. A holding fixture allowed for minor adjustment of the heat pipe elevation above or below horizontal. The holding fixture was designed to minimize contact with the face sheet, minimize thermal conductance between face sheet and fixture, and maximize unobstructed view to the cold walls. No additional sources of illumination were added to the facility at this point.

The first goal of this effort was to identify heat transfer rate (in watts) as a function of temperature (in K). The panels were heated at multiple power inputs between 200 and 400 watts, reaching steady state for each power input. Typically three power inputs were used. Heat transfer rate as a function of temperature was obtained at steady state on a per heat pipe basis, plotted as a function of panel, and compared to the theoretical performance expected from a grooved heat pipe based on modeling. The second goal was to identify thermal resistance between heat pipe and face sheet. Thermal resistance, (K/watt), is visualized graphically along the panel at multiple wattage inputs utilizing steady state temperatures location-averaged with respect to the three heat pipes in that panel. The third goal was to compare panel performance as a function of wick configuration and polymer matrix composite. This was accomplished through observation. The fourth goal was to examine off nominal panel performance, including loss of a heat pipe and cold start. A simulated heat pipe failure was achieved by turning off the power to the center heat pipe of panel A and observing the change in panel temperature at steady state. Face sheet temperature drop was identified as a function of location with respect to the null heat pipe. Cold start was accomplished by allowing the panel to cool to below freezing and slowly bringing the panel back on line with small increments of power. In addition, finite difference analysis modeling was conducted utilizing a desktop finite differencing analysis model incorporating the thermal characteristics of the panel's constituent parts. Repeated exercising of the model allowed modeling results and test results to converge to within a few percent.

Thermal Desktop ${ }^{\circledR}$, a product of C\&R Technologies, was used to model each panel and the modeling echoed geometric parameters where possible, including panel width, length, heat pipe diameter, heat pipe wall thickness, POCO graphite width and height, and face sheet thickness. Adhesive thickness in the model was $0.127 \mathrm{~mm}$. The thermal desktop modeling also echoed physical properties, at temperature were possible, including thermal conductivity of the titanium, POCO graphite, and polymer matrix composite face sheets. Convergence of the modeling data with the as-measured steady state heat pipe temperatures was accomplished by exercising the model repeatedly, changing the contact conductance through the adhesive layer, in essence, the areal density of the graphite foam making contact with its respective surface, the titanium heat pipe or the polymer matrix composite.

\section{Results and Discussion}

In general, panel testing proceeded for Panels A and B as planned. Panel C suffered from the formation of a non-condensable gas in its heat pipes due to contamination resulting in irreparable damage to the completed panel assembly. No testing on Panel C was conducted.

Each panel was designed to reject 1500 watts of power at $500 \mathrm{~K}, 500$ watts per heat pipe. However, the heat pipes did not perform to the predicted 500 watts each, rather, their performance was limited to the 300 watt range. In essence, the panels were oversized and could not reach there design temperature under thermal vacuum heat rejection conditions.

\section{A. Masked Panel Operation}

Baseline operation of panels A and B revealed an inability to reach the design point of $500 \mathrm{~K}$. In an attempt to achieve this design point in practice, the panels were purposely covered in aluminum foil to block off approximately 
$40 \%$ of the panel surface. Figure 3 shows one of the panels so masked. It was found that heat pipe performance was the limiting factor, not panel size, as the maximum individual heat pipe performance with panel masked was only in the mid 300 watt range.

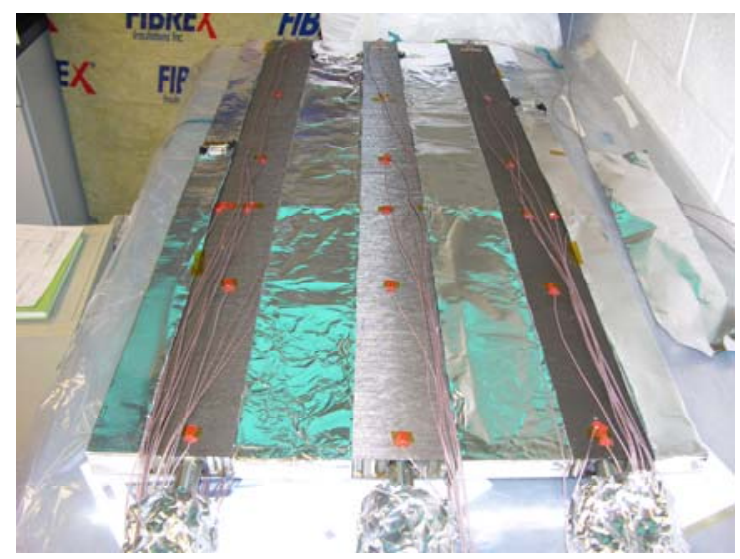

Figure 3. Panel A masked with aluminum foil.

\section{B. Heat Transfer Rate as a Function of Temperature}

Heat pipe performance is limited by a number of factors. ${ }^{9}$ First is evaporator dry-out. In dry-out, heat entering the heat pipe vaporizes the working fluid at a rate faster than the working fluid is being returned from the condenser, in essence, starving the evaporator of working fluid. Ideal heat pipe operation occurs just prior to evaporator dryout. Next is entrainment. Vapor traveling down the length of the heat pipe can reach sonic values, and can entrain a portion of the liquid in the condenser section, which decreases working fluid return to the evaporator. Identifying the amount of working fluid to use when charging the heat pipe is critical in eliminating entrainment. Other thermophysical processes critical to heat pipe operation include: heat flow through the walls of the evaporator to the working fluid, boiling phenomenon at the liquid-vapor interface in the evaporator, condensation phenomenon at the vapor-liquid interface in the condenser, and contact angle of the working fluid with respect to the wick configuration. In aggregate, many of the physical phenomena are temperature dependent, so the power carried by a heat pipe is expected to be non-linear with temperature.

Heat transfer rate through the heat pipe, in watts, is plotted as a function of temperature in Figure 4. The solid line in Figure 4 depicts the power carried by the notionally ideal solid axial groove titanium - water heat pipe utilized here. As-measured steady state performance data are added to Figure 4 as individual points. Wattage

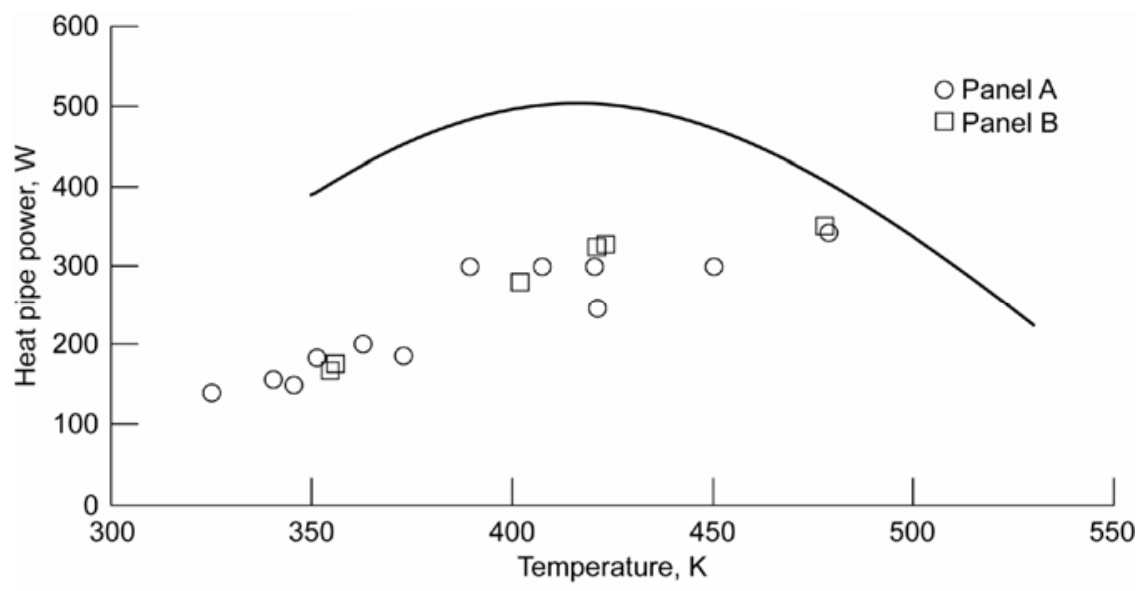

Figure 4. Calculated steady-state heat pipe power as a function of temperature. 
values passing through the heat pipe were identified with the aid of modeling, utilizing the as-measured wattage and deducting a fraction of the heat attributed to losses from the heaters down the heater power leads and through the insulation until condenser temperatures in the model matched the as-measured condenser temperatures. For panel A, the losses were approximately $3 \%$ while for panel B, the losses were approximately $10 \%$.

\section{Thermal Resistance Between Heat Pipe and Face Sheet}

The thermal resistivity of a system is defined as the reciprocal of thermal conductivity, $\mathrm{k}$, which is given in units of watts/m K. Equation 1 utilizes thermal conductivity as a proportionality constant, and indicates the importance of cross sectional area through which the heat must pass and the length through which it must travel:

$$
\text { Watts }=\mathrm{k} \text { (Area) }(\text { Temperature }) /(\text { Length })
$$

In a system composed of a heat pipe and face sheet, heat is delivered to the system via a line source of essentially uniform temperature, the condenser section of the heat pipe. The area of the system through which heat is being rejected is constant. By operating the system at steady state, i.e. constant heat input in watts, the temperature and length constituents can be visualized in three dimensions by plotting temperature as a function of location. Differences in temperature depict thermal resistance, with greater temperature differences depicting greater thermal resistance. Location-averaged steady state temperature data from the three heat pipes in Panel A and the three heat pipes in panel B are summarized in Figures 5a through 5e at different operating conditions.

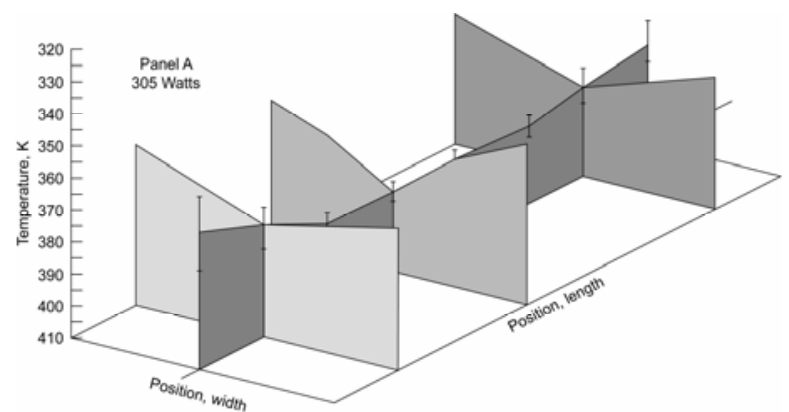

b) Panel A operating at 305 watts.

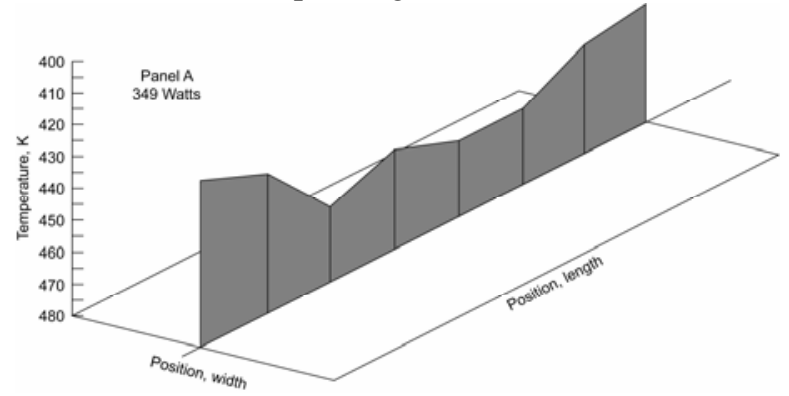

d) Panel A operating at 349 watts (masked).

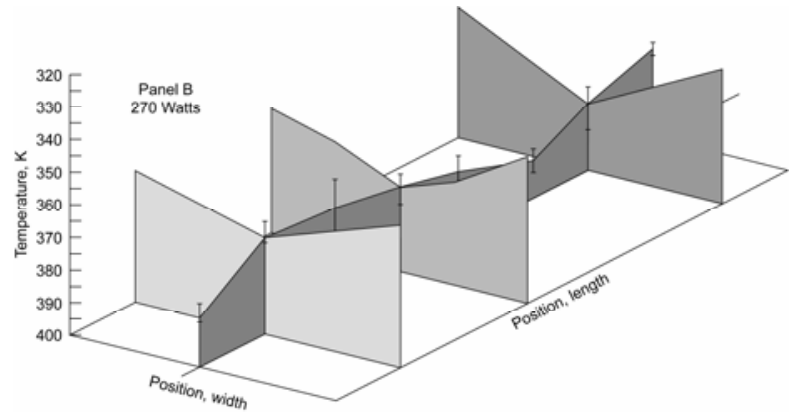

a) Panel B operating at 270 watts

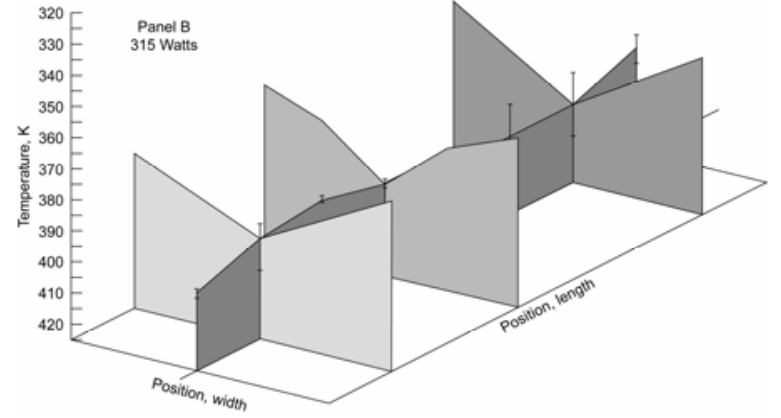

c) Panel B operating at 315 watts.

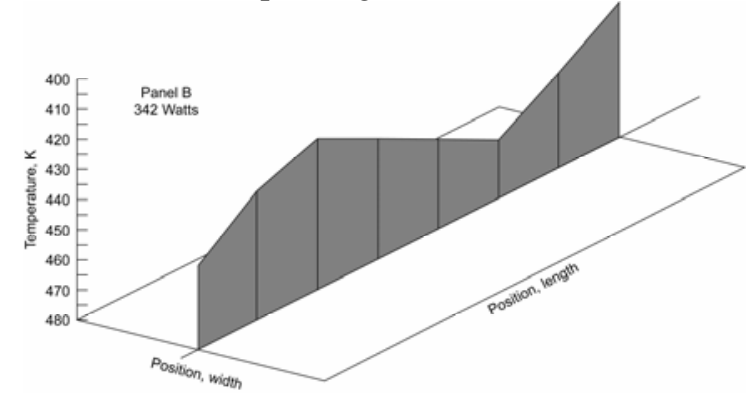

e) Panel B operating at 342 watts (masked).

Figure 5. Thermal resistance as a function of location. 
Condenser temperatures as measured at each end of the condenser section were found to be within a few degrees of each other. These temperatures were averaged to identify the average temperature of the line source, shown here as a plane at the bottom of each figure. By far, the greatest temperature drop in the system is through the POCO graphite saddle, which includes the adhesive interface between titanium and POCO graphite and POCO graphite and composite. Interestingly, the ends of the panel in general appear to be in poorer thermal contact than the center, suggesting the assembly process yields a better bond in the center of the panel. The error bars along the centerline of each figure represent the variability in face sheet temperature from one heat pipe to another, as installed in a single panel, and suggest variability in the manufacturing process of the composite panel not variability in the manufacturing process of heat pipes. Temperatures along the face sheet extending axially from the line source were remarkably similar at the three axial planes depicted in the figures indicating the high thermal conductivity fibers were working as expected, spreading heat across the panel from the line source. One can also conclude that the face sheet performance from one panel to another was similar, as indicated by similar temperature profiles along the three axial planes.

\section{Panel Performance as a Function of Wick Configuration and Polymer Matrix Composite}

The axial groove heat pipe wick configurations used in panels A and B had similar performance. Similar performance of the polymer matrix composite face sheets was also observed. Of the two panels, panel A using HFPE exhibited signs of delamination after repeated vacuum thermal cycling, while panel B using 5250-4 BMI showed no signs of delamination after testing.

\section{E. Off Nominal Panel Performance}

Two off nominal performance tests were conducted, loss of a heat pipe and cold start. For loss of a heat pipe, the center heat pipe of panel A was shut down after all three heat pipes reached steady state, each at 300 watts. With the loss of the center heat pipe the temperature of the face sheet dropped by about $28 \mathrm{~K}$ in the vicinity of the still working neighbors while it dropped by about $70 \mathrm{~K}$ in the region above the null heat pipe.

Cold start was attempted, however, it was not achieved for the fully charged heat pipes suggesting the need for illumination or an auxiliary heater to supply power to at least one heat pipe for starting from the frozen state. Such cold start accommodations need to be considered for lunar operations.

\section{Future Work}

Titanium offers excellent burst strength versus weight. However, it offers rather poor thermal conductivity. This, combined with the disappointing thermal conductance through the POCO graphite and adjoining adhesive layers resulted in a much larger than anticipated thermal resistance from heat pipe to face sheet. The source of the problem was the poor conductance through the adhesive layers and the low areal density of contact of the POCO graphite at its interfaces. Additional work is needed to better connect, thermally, the heat pipe to the face sheet. Candidate concepts include use of high thermal conductivity adhesives and improved saddle materials.

Mass to the lunar surface trades against structural integrity during launch and deployment. Additional trade studies are needed to identify new panel geometries that yield the benefits of multifunctional use, rather than the traditional honeycomb sandwich structure in use today.

Key to understanding radiator performance on the lunar surface will be an understanding and simulation of the sink temperature conditions found at any given location throughout the year. Plans are under way to upgrade the thermal vacuum facility used here to include multiple lamps for the purpose of varying sink temperature to simulate lunar sunrise and sunset, and to test the RDU panels studied here at varying sink temperatures.

\section{Conclusion}

A technology development program is underway at NASA Glenn Research Center to evaluate the performance of radiator panels for the lunar surface. Titanium - water heat pipes offer the promise of micrometeoroid impact tolerance, while polymer matrix composite panels offer the promise of reducing mass and increasing performance over aluminum. Heat pipe performance was evaluated in a thermal vacuum chamber and maximum performance was found to be approximately 350 watts per heat pipe at a temperature of $480 \mathrm{~K}$. Panel performance was mixed. The high thermal conductivity fibers used in the face sheets performed the job of spreading heat successfully, independent of the polymer matrix utilized. However, the graphite saddles and adhesives selected to make the thermal connection between heat pipe and face sheet were disappointing. An unexpectedly high thermal resistance was found across the heat pipe to face sheet interface and the source of the problem was attributed to the poor 
conductance through the adhesive layers and the low areal density of contact between the POCO graphite and its interfaces. Off nominal panel performance successfully simulated a micrometeoroid strike, however, cold start was problematic. Future work is needed to improve the thermal conductance between heat pipe and face sheet. An upgrade to the thermal vacuum chamber is planned to vary sink temperatures to simulate lunar sunrise and sunset.

\section{References}

${ }^{1}$ Mason, L. S., “A Comparison of Fission Power System Options for Lunar and Mars Surface Applications,” Space Technology and Applications International Forum - 2006, edited by M.S. El-Genk, American Institute of Physics, Albuquerque, NM, 2006, pp. 270-280.

${ }^{2}$ Siamidis, J., and Mason, L., “A Comparison of Coolant Options for Brayton Power Conversion Heat Rejection Systems,” Space Technology and Applications International Forum - 2006, edited by M.S. El-Genk, American Institute of Physics, Albuquerque, NM, 2006, pp. 682-693.

${ }^{3}$ Anderson, W. G., Dussinger, P. M., Bonner, R. W., and Sarraf, D. B., "High Temperature Titanium-Water and Monel-Water Heat Pipes,” International Energy Conversion Engineering Conference, AIAA, San Diego, CA, 2006, pp 828-839.

${ }^{4}$ Rosenfeld, J. H., and Gernert, N. J., “Advances in High Temperature Titanium-Water Heat Pipe Technology,” Space Technology and Applications International Forum - 2007, edited by M.S. El-Genk, American Institute of Physics, Albuquerque, NM, 2007, pp. 129-136.

${ }^{5}$ Sanzi, J. L., "Thermal Performance of High Temperature Titanium-Water Heat Pipes by Multiple Heat Pipe Manufacturers," Space Technology and Applications International Forum - 2007, edited by M.S. El-Genk, American Institute of Physics, Albuquerque, NM, 2007, pp. 681-691.

${ }^{6}$ Juhasz, A. J., and Rovang, R., “Carbon-Carbon Heat Pipe Testing and Evaluation,” NASA TM-106630, 1994.

${ }^{7}$ Miller, W. O., Wang, M, Shih, W., Ramirez, R., Beach, D, Youchison, D., Lenard, R., Liguori, J., and Liguori, E., “An Ultra-Lightweight, High Performance Carbon-Carbon Space Radiator,” Space Technology and Applications International Forum - 2007, edited by M.S. El-Genk, American Institute of Physics, Albuquerque, NM, 2007, pp. 421-429.

${ }^{8}$ Anderson, W. G., Sarraf, D. B., and Garner, S. D., "High Temperature Water-Titanium Heat Pipe Radiator," International Energy Conversion Engineering Conference, AIAA, San Diego, CA, 2006, pp 1038-1046.

${ }^{9}$ Dunn, P. D., and Reay, D. A., Heat Pipes, $3^{\text {nd }}$ ed., Pergamon Press, Oxford, 1982, pp. 1-308. 